\title{
PERSEPSI DAN PARTISIPASI MASYARAKAT DALAM PENGEMBANGAN AIR TERJUN MANUSAMA DI DESA URENG KABUPATEN MALUKU TENGAH
}

\author{
COMMUNITY PARTICIPATION IN MANUSAMA WATERFALL MANAGEMENT IN \\ URENG VILLAGE, CENTRAL MALUKU DISTRICT
}

\author{
Yemima Matulessy ${ }^{1)}$, Debby Pattimahu ${ }^{2)}$, Yosevita. Latupapua ${ }^{3)}$ \\ ${ }^{1)}$ Mahasiswa Pascasarjana Prodi Manajemen Hutan Universitas Pattimura \\ ${ }^{2,3)}$ Dosen Pascasarjana Program Studi Manajemen Hutan Universitas Pattimura \\ Email: yemimamatulessy@yahoo.com

\begin{tabular}{l|l}
\hline Diterima: 13 Juli 2018 & Disetujui: 30 Juli 2018
\end{tabular}

\begin{abstract}
Abstrak
Air terjun Manusama merupakan suatu kawasan objek air terjun alami yang saat ini mendapat perhatian pemerintah daerah dalam pengembangan. Sebagai langkah awal dalam pengembangan objek ekowisata, terlebih dulu harus diketahui persepsi dan peran serta masyarakat terkait pengembangan. Adapun tujuan dalam penelitian ini adalah menganalisis persepsi dan peran serta masyarakat Desa Ureng Dalam Pengembangan Air Terjun Manusama. Metode penelitian yang dilakukan adalah metode deskriptif kualitatif. Data dikumpulkan dalam bentuk data primer dan data sekunder. Data primer merupakan data observasi dan wawancara terkait bentuk partisipasi masyarakat dalam pengembangan objek, dan pengisian kuisioner terkait persepsi dalam pengembangan. Sedangkan data sekunder terkait bentuk partisipasi dalam laporan desa. Hasil penelitian menunjukkan bahwa persepsi masyarakat dalam pengembangan objek dan atraksi berada pada kriteria setuju (S) dengan nilai $(3475,2)$, persepsi dalam pengembangan fasilitas memiliki nilai $(3301,3)$ dengan kriteria sesuai (S) dan persepsi dalam pengembangan aksesibilitas dengan nilai $(3830,2)$ berada pada kriteria sangat sesuai (SS). Hasil penilaian partisipasi masyarakat dalam perencanaan memiliki kriteria sesuai (S) dengan nilai $(3002,4)$, sedangkan hasil penilaian partisipasi dalam pengelolaan memiliki kriteria sangat sesuai (SS), dengan nilai $(3864,4)$.
\end{abstract}

Kata kunci: Persepsi masyarakat, Air Terjun Manusama,

\begin{abstract}
Manusama Waterfall is an area of natural waterfall object which is currently getting the attention of local governments in development. As a first step in developing ecotourism objects, it must first be known the perceptions and participation of the community regarding development. The purpose of this study was to analyze perceptions and participation of the Ureng Village community in Manusama Waterfall Development. The research method used is a qualitative descriptive method. Data is collected in the form of primary data and secondary data. Primary data is observation and interview data related to the form of community participation in object development, and filling in questionnaires related to perceptions in development. While secondary data is related to the form of participation in village reports. The results showed that community perceptions in the development of objects and attractions were on agreed criteria (S) with values (3475.2), perceptions in facility development had a value (3301.3) with the appropriate criteria (S) and perceptions in accessibility development with values (3830.2) are in the very appropriate criteria (SS). The results of the assessment of community participation in planning have criteria according to (S) with a value (3002.4), while the results of the assessment of participation in management have a very appropriate criteria (SS), with a value (3864.4)
\end{abstract}

Keywords: Public perception, Manusama Waterfall, 


\section{PENDAHULUAN}

Pengembangan ekowisata saat ini merupakan salah satu bentuk dari pariwisata berkelanjutan (Haribawa et.al., 2018). Pengembangan ekowisata sedang marak dilakukan hampir diseluruh pelosok tanah air Indonesia, termasuk di Provinsi Maluku. Desa Ureng merupakan salah satu desa yang didalamnya tersimpan pesona daya tarik ekowisata andalan yaitu Air terjun Manusama atau lebih populer di kenal Air Terjun Ureng. Desa Ureng merupakan salah satu desa yang berada dalam daerah administratif Kabupaten Maluku Tengah yang saat ini mulai dikembangkan sebagai objek daya tarik ekowisata karena memiliki objek air terjun alami, yang mulai mendapat perhatian Pemerintah Daerah dalam pengembangan produk daya tarik wisata.

Potensi Air Terjun Manusama ini didukung pula oleh potensi daya tarik lainnya yang dapat dinikmati ketika ada dalam aktifitas wisata ke desa antara lain, kealamian desa yang terkesan alami dengan udaranya yang bersih, keindahan alamnya yang beragam (bukit, pantai dan laut) serta kehidupan sosial budaya masyarakat yang tercermin dalam aktifitas hidup masyarakat yang hidup rukun dan bersahaja. Namun dalam perkembangannya, potensi daya tarik tersebut ternyata belum dimanfaatkan secara optimal untuk mendatangkan sejumlah wisatawan, sehingga nilai tambah dan manfaat dari ekowisata pun belum dapat dinikmati dan dirasakan oleh masyarakat. Hal ini didukung juga dalam penelitian Wihadanto dan Firmansyah (2013), bahwa perlu adanya upaya untuk mengembangkan destinasi wisata guna mendorong para wisatawan untuk tinggal dan berkunjung, sehingga dapat mendorong peningkatan perekonomian dan mengurangi ketimpangan.

Sebagai langkah awal untuk mengembangkan objek daya tarik ekowisata, yang terpenting adalah mengetahui ada tidaknya kehendak bersama (common will) antara masyarakat Desa Ureng untuk mengembangkan produk daya tarik Air Terjun Manusama. Melalui kajian orientasi, kita dapat mengetahui arah dan sikap masyarakat apakah telah mengarah pada koridor dan prinsip-prinsip pembangunan ekowisata (Haribawa et.al., 2018). Brahmantyo et al., (2017) mengemukakan bahwa mempelajari persepsi, pemikiran dan sikap masyarakat dalam pengembangan destinasi pariwisata menjadi penting untuk 
dilakukan, karena dapat menggambarkan seberapa besar dukungan yang diberikan untuk keberhasilan pembangunan pariwisata. tujuan dalam penelitian ini yaitu menganalisis persepsi dan peran serta masyarakat dalam pengelolaan ekowisata Air Terjun Manusama Desa Ureng Kabupaten Maluku Tengah. Manfaat

\section{METODE PENELITIAN}

Penelitian dilakukan di lokasi Air Terjun Manusama Desa Ureng, Kabupaten Maluku Tengah. Pemilihan lokasi penelitian didasarkan atas pertimbangan, yaitu: 1) desa tersebut dikategorikan sebagai desa adat yang selama ini masyarakat desanya bertanggungjawab dalam pengelolaan Air Terjun Manusama; 2) memiliki sumberdaya alam dan budaya yang potensial untuk dijadikan objek dan daya tarik ekowisata; dan 3) lokasi penelitian merupakan salah satu jalur utama perlintasan wisatawan menuju objek wisata unggulan di Pulau Tiga wisata (Pantai Nusaela). Penelitian ini menggunakan pendekatan fenomenologi, yaitu sebuah pendekatan yang mempelajari fenomena manusia dan perilaku-perilaku sosial (Gill dan Johnson 1997 dalam Haribawa et al., 2018)).

Dalam pendekatan fenomenologi, seorang peneliti mencoba memahami dan menafsirkan apa dan mengapa fenomena penelitian yaitu: (1) memberikan arahan rekomendasi tentang persepsi dan peran masyarakat desa dalam pengembangan dan Pengelolaan; (2) sebagai landasan bagi pengambil kebijakan dalam merancang pembangunan ekowisata berkelanjutan di Kabupaten Maluku Tengah.

itu terjadi, yang bersumber pada partisipan (Easterby-Smith et al., 1999 dalam Haribawa et al., 2018). Fenomena yang akan dipahami dalam penelitian ini adalah berkaitan dengan orientasi masyarakat Desa Ureng dalam pengembangan dan pengelolaan Air Terjun Manusama. Orientasi masyarakat dapat diidentifikasi melalui persepsi dan peran serta dalam rencana pengembangan produk daya tarik ekowisata.

Populasi dalam penelitian ini adalah Masyarakat Desa Ureng. Sampel dipilih menggunakan simple random sampling, di mana pengambilan anggota sampel dari populasi dilakukan secara acak tanpa memperhatikan strata yang ada dalam populasi itu (Sugiyono 2010). Sampel masyarakat diambil secara acak dalam desa yaitu 30 responden untuk masyarakat desa. Sedangkan sampel pemerintah diambil secara acak mulai dari tingkat pemerintah desa hingga tingkat 
kabupaten sebanyak 6 orang, sehingga total responden yang dijadikan sampel berjumlah 36 orang. Ada dua data penting yang diambil untuk menganalisis orientasi masyarakat erkait pengelolaan ekowisata, yaitu:persepsi dan peran serta. Data persepsi yang diambil berkaitan dengan pandangan masyarakat mengenai perencanaan pengembangan objek, fasilitas dan aksesibilitas. Sedangkan data peran serta berkaitan dengan bentuk aksi yang dilakukan atau akan dilakukan dalam pengelolaan ekowisata di objek ekowisata Desa Ureng. Data persepsi dan peran serta, masing-masing terdiri dari tujuh pertanyaan, sehingga total pertanyaan yang diajukan kepada responden berjumlah 7 pertanyaan.

Teknik pengumpulan data dilakukan dengan menggunakan kuesioner tertutup. Skala pengukuran sikap yang digunakan pada kuesioner adalah skala Likert yang di modifikasi oleh Avenzora.
Dalam penelitian ini, rentang skala yang digunakan adalah 1-7 (merupakan pengembangan dari skala Likert 1-5) (Avenzora 2008). Untuk data persepsi, keterangan skor yang digunakan, yaitu : 1=sangat tidak setuju, 2=tidak setuju, 3=kurang setuju, 4=biasa saja, 5=agak setuju, $6=$ setuju dan $7=$ sangat setuju. Sedangkan data motivasi, skor yang digunakan, yaitu : 1=sangat rendah, 2=rendah, 3=agak rendah, 4=biasa saja, 5=agak tinggi, $6=$ tinggi, dan $7=$ sangat tinggi. Analisis data yang digunakan dalam penelitian ini adalah analisis deskriptif. Analisis ini menggunakan pengelompokkan, penyederhanaan, serta penyajian data menggunakan interval kelas dan garis kontinum. Untuk mengukur persepsi dan peran serta stakeholders, digunakan asumsi dasar interval kelas, maka dapat dibuat kategori dan garis kontinum pada variabel persepsi dan peran serta seperti pada Tabel 1.

Nilai maksimal==Skor tertinggi $\mathrm{x}$ jumlah sampel $\mathrm{x}$ jumlah pertanyaan

Nilai minimal $==$ Skor terendah $\mathrm{x}$ jumlah sampel $\mathrm{x}$ jumlah pertanyaan

Rentang kelas $=$ Jumlah nilai tertinggi - jumlah nilai terendah

$$
\text { Jumlah skor }
$$

Tabel.1. Interval Kelas Berdasarkan Skala Nilai Persepsi dan Peran Serta.

\begin{tabular}{lclll}
\hline \multicolumn{2}{c}{ Persepsi } & \multicolumn{2}{c}{ Peran Serta } \\
\hline Sangat Setuju (SS) & $:$ & $3.834,6-4.410$ & Sangat Setuju (SS) & $3.834,6-4.410$ \\
Setuju (S) & $:$ & $3.294,5-3.834,6$ & Setuju (S) & $3.294,5-3.834,6$ \\
Agak Setuju (AS) & $:$ & $2.754,4-3.294,5$ & Agak Setuju (AS) & $2.754,4-3.294,5$ \\
Biasa Saja (BS) & $:$ & $2.214,3-2.754,4$ & Biasa Saja (BS) & $2.214,3-2.754,4$ \\
Kurang Setuju (KS) & $:$ & $1.674,2-2.214,2$ & Kurang Setuju (KS) & $1.674,2-2.214,2$ \\
Tidak Setuju (TS) & $:$ & $1.170,1-1.674,1$ & Tidak Setuju (TS) & $1.170,1-1.674,1$ \\
\hline
\end{tabular}




\begin{tabular}{llll}
\hline Sangat Tidak Setuju (STS): & $630-1.170$ & Sangat Tidak Setuju (STS) & $630-1.170$
\end{tabular}

\section{HASIL DAN PEMBAHASAN}

Persepsi Stakeholders Terkait Pengembangan Objek Ekowisata

$$
\text { Penilaian persepsi masyarakat }
$$
Desa Ureng mengenai konsep

terkait pengembangan produk daya tarik ekowisata menjadi penting untuk dilakukan guna memperoleh gambaran

awal tentang pengetahuan masyarakat pengembangan objek dan atraksi ekowisata. Indikator persepsi masyarakat dalam pengembangan objek dan atraksi wisata tersaji pada Tabel.2:

Tabel. 2. Indikator Persepsi Stakeholders Untuk Pengembangan Objek dan Atraksi Wisata

\begin{tabular}{|c|c|c|c|c|c|c|c|c|}
\hline \multirow[t]{2}{*}{ No. } & \multirow[t]{2}{*}{ Persepsi Pengembangan Objek dan Atrksi } & \multicolumn{7}{|c|}{ Skor Penilaian } \\
\hline & & $\begin{array}{l}\text { SS } \\
\text { (7) }\end{array}$ & $\begin{array}{c}S \\
(6)\end{array}$ & $\begin{array}{l}\text { AS } \\
\text { (5) }\end{array}$ & $\begin{array}{l}\text { BS } \\
\text { (4) }\end{array}$ & $\begin{array}{l}\text { KS } \\
\text { (3) }\end{array}$ & $\begin{array}{l}\text { TS } \\
\text { (2) }\end{array}$ & $\begin{array}{c}\text { STS } \\
\text { (1) }\end{array}$ \\
\hline 1 & $\begin{array}{l}\text { Pengembangan lebih difokuskan pada objek dan } \\
\text { atraksi pendukung selain air terjun, antara lain } \\
\text { pengamatan objek birdwatching dan atraksi seni } \\
\text { budaya lokal. }\end{array}$ & & & & & & & \\
\hline 2 & $\begin{array}{l}\text { Pengembangan objek dan atraksi tidak merusak } \\
\text { atau merubah lingkungan ekosistem sekitar }\end{array}$ & & & & & & & \\
\hline 3 & $\begin{array}{l}\text { Pengembangan objek dan daya tarik dilakukan } \\
\text { dengan melibatkan ide masyarakat lokal }\end{array}$ & & & & & & & \\
\hline 4 & $\begin{array}{l}\text { Pengembangan objek dan daya tarik disesuaikan } \\
\text { dengan karakteristik alam dan budaya lokal, bukan } \\
\text { mengadop budaya lain }\end{array}$ & & & & & & & \\
\hline 5 & $\begin{array}{l}\text { Pengembangan objek dan atraksi disesuaikan } \\
\text { dengan kapasitas masyarakat Desa Ureng }\end{array}$ & & & & & & & \\
\hline 6 & $\begin{array}{l}\text { Pengembangan objek dan atraksi budaya } \\
\text { disesuaikan dengan aturan adat maupun aturan } \\
\text { agama }\end{array}$ & & & & & & & \\
\hline 7 & $\begin{array}{l}\text { Pengembangan objek dan atraksi memiliki } \\
\text { dampak mendukung aturan adat, budaya dan } \\
\text { agama }\end{array}$ & & & & & & & \\
\hline
\end{tabular}

Sumber; Data Primer, 2017

Berdasarkan pada hasil analisis dalam penelitian dapat dijelaskan bahwa persepsi masyarakat terkait pengembangan objek dan atraksi dalam menunjang ekowisata air terjun Desa Ureng mendapat skor setuju (S) sebesar 3.475,2. Data ini menunjukkan bahwa pemerintah dan masyarakat Desa Ureng setuju untuk mendukung pengembangan objek dan atraksi wisata dalam menunjang objek andalan Air Terjun Manusama. Perlunya pengembangan objek dan atraksi pendukung ini sesuai dengan pendapat Damanik dan Webber (2006), yang mengemukakan bahwa produk daya tarik wisata harus memiliki keragaman objek 
dan atraksi wisata sehingga menambah nilai jual suatu kawasan wisata dan dapat mempengaruhi lama tinggal wisatawan (length of stay). Marpaung (2017) dalam penelitian juga mengemukakan bahwa Ada beberapa fenomena yang harus diperhatikan dalam penataan pariwisata di antaranya daya tarik, baik berupa keindahan alamnya maupun masyarakat dan budayanya karena merupakan satu paket yang tidak terpisahkan sehingga orang-orang atau wisatawan tertarik untuk berkunjung ke daerah tersebut. Sedangkan

\section{Persepsi Masyarakat Terkait Pengembangan Fasilitas Ekowisata}

Penilaian persepsi masyarakat terkait pengembangan Fasilitas ekowisata menjadi penting untuk dilakukan guna mendapatkan gambaran penilaian secara menyeluruh dalam proses pengembangan, bentuk fasilitas yang menjadi kebutuhan dalam menunjang aktifitas pengunjung.
Haribawa et al., (2018) dalam penelitian menjelaskan bahwa persepsi perlu dilakukan untuk mengetahui konsep ekowisata dapat dijadikan sebagai acuan dalam menciptakan lingkungan yang berkelanjutan (baik dari sisi ekonomi, ekologi dan sosial budaya), menumbuhkan pendidikan konservasi serta memberikan kepuasan dan pengalaman yang menarik bagi wisatawan; dan 2) masyarakat dan pemerintah memiliki pandangan kognitif yang positif dan selaras terhadap konsep ekowisata.

jual tinggi, perlu ditunjang bukan hanya oleh keragaman objek dan atraksi, namun harus dilengkapi dengan fasilitas dan aksesibilitas (Damanik dan Weber, 2006). Dalam mengungkapkan persepsi masyarakat dalam pengembangan fasilitas wisata dilakukan melalui 7 (tujuh) indikator pertanyaan yang tersaji pada Tabel. 3:

Objek yang berkualitas dan memiliki nilai

Tabel 3. Indikator Persepsi Stakeholders Untuk Pengembangan Fasilitas Wisata

\begin{tabular}{|c|c|c|c|c|c|c|c|c|}
\hline \multirow[t]{2}{*}{ No. } & \multirow[t]{2}{*}{ Persepsi Pengembangan Fasilitas Wisata } & \multicolumn{7}{|c|}{ Skor Penilaian } \\
\hline & & $\begin{array}{l}\text { SS } \\
\text { (7) }\end{array}$ & $\begin{array}{c}S \\
\text { (6) }\end{array}$ & $\begin{array}{l}\text { AS } \\
\text { (5) }\end{array}$ & $\begin{array}{l}\text { BS } \\
\text { (4) }\end{array}$ & $\begin{array}{l}\text { KS } \\
\text { (3) }\end{array}$ & $\begin{array}{l}\text { TS } \\
\text { (2) }\end{array}$ & $\begin{array}{c}\text { STS } \\
\text { (1) }\end{array}$ \\
\hline 1 & $\begin{array}{l}\text { Pengembangan lebih difokuskan pada fasilitas } \\
\text { wisata antara lain shelter/gasebo, kamar mandi, } \\
\text { warung makan, parkiran. }\end{array}$ & & & & & & & \\
\hline 2 & $\begin{array}{l}\text { Pengembangan fasilitas wisata tidak merusak atau } \\
\text { merubah lingkungan ekosistem sekitar }\end{array}$ & & & & & & & \\
\hline 3 & $\begin{array}{l}\text { Pengembangan fasilitas wisata dilakukan dengan } \\
\text { melibatkan ide masyarakat lokal }\end{array}$ & & & & & & & \\
\hline 4 & $\begin{array}{l}\text { Pengembangan fasilitas wisata menggunakan } \\
\text { bahan ramah lingkungan dan memiliki tingkat } \\
\text { emisi yang rendah (bambu/rotan/atap) }\end{array}$ & & & & & & & \\
\hline
\end{tabular}


$5 \quad$ Pengembangan fasilitas wisata disesuaikan dengan daya dukung kawasan

$6 \quad$ Pengembangan fasilitas wisata disesuaikan dengan arsitektur lokal

7 Pengembangan fasilitas wisata dilakukan sepenuhnya oleh masyarakat Desa Ureng

Sumber: Data Primer 2017

Hasil penelitian berdasarkan indikator persepsi dalam pengembangan fasilitas dari 7 kriteria penilaian adalah berada pada kategori setuju (S) dengan nilai sebesar 3.301,3. Data tersebut menjelaskan bahwa masyarakat memahami bahwa pengembangan fasilitas wisata perlu dilakukan dalam menunjang aktifitas pengunjung selama melakukan kunjungannya ke Air Terjun Manusama. Di samping itu pengembangan fasilitas wisata merupakan suatu bentuk daya tarik wisata yang dapat mempengaruhi minat dan motivasi berkunjungan serta kepuasan wisatawan (Damanik dan Weber, 2006). Haribawa (2018) menjelaskan bahwa Jika masyarakat memiliki orientasi yang berbeda-beda dalam kegiatan

\section{Persepsi Masyarakat Terkait Pengembangan Aksesibilitas Ekowisata}

Penilaian persepsi masyarakat terkait pengembangan aksesibilitas menjadi penting untuk dilakukan guna mendapatkan gambaran persepsi penilaian secara menyeluruh dalam proses pengembangan suatu objek daya tarik. Objek yang berkualitas dan pengembangan, maka akan berdampak pada tidak optimalnya berbagai program yang nantinya akan dijalankan. Hasil penelitian yang sama juga dijelaskan dalam penelitian Muslih (2015), bahwa jika setiap pihak berjalan secara sporadis dan mempunyai persepsi serta kepentingan masing-masing yang tidak selaras, maka dapat dipastikan pengembangan tidak dapat berjalan secara optimal dan berkelanjutan.

Kondisi di lapangan menggambarkan bahwa ada kesepahaman persepsi dari seluruh responden dalam memberikan tanggapan bahwa penngembangan fasilitas perlu dilakukan dan disesuaikan dengan daya dukung dan kebutuhan pengunjung dalam menikmati aktifitas wisatanya.

memiliki nilai jual tinggi, tentunya perlu ditunjang bukan hanya oleh keragaman objek dan atraksi, namun harus dilengkapi dengan fasilitas dan aksesibilitas (Damanik dan Weber, 2006). Dalam mengungkapkan persepsi dalam pengembangan aksesibilitas dilakukan melalui 7 (tujuh) indikator pertanyaan yang tersaji pada Tabel. 4: 
Tabel 4. Indikator Persepsi Stakeholders Untuk Pengembangan Aksesibilitas Wisata

\begin{tabular}{|c|c|c|c|c|c|c|c|c|}
\hline \multirow[t]{2}{*}{ No. } & \multirow[t]{2}{*}{ Persepsi Pengembangan Fasilitas Wisata } & \multicolumn{7}{|c|}{ Skor Penilaian } \\
\hline & & $\begin{array}{l}\text { SS } \\
\text { (7) }\end{array}$ & $\begin{array}{l}\mathrm{S} \\
(6)\end{array}$ & $\begin{array}{l}\mathrm{AS} \\
(5)\end{array}$ & $\begin{array}{l}\mathrm{BS} \\
(4)\end{array}$ & $\begin{array}{l}\mathrm{KS} \\
(3)\end{array}$ & $\begin{array}{l}\text { TS } \\
\text { (2) }\end{array}$ & $\begin{array}{c}\text { STS } \\
(1)\end{array}$ \\
\hline 1 & $\begin{array}{l}\text { Pengembangan lebih difokuskan pada penataan } \\
\text { jalan setapak menuju ke Air Terjun Manusama. }\end{array}$ & & & & & & & \\
\hline 2 & $\begin{array}{l}\text { Pengembangan jalan tidak merusak atau merubah } \\
\text { lingkungan ekosistem sekitar }\end{array}$ & & & & & & & \\
\hline 3 & $\begin{array}{l}\text { Pengembangan jalan dilengkapi dengan } \\
\text { penambahan moda transportasi darat (tambahan } \\
\text { trayek Ambon-Ureng) }\end{array}$ & & & & & & & \\
\hline 4 & $\begin{array}{l}\text { Pengembangan jembatan gantung menggunakan } \\
\text { bahan ramah lingkungan dan memiliki tingkat } \\
\text { emisi yang rendah (bambu/rotan) }\end{array}$ & & & & & & & \\
\hline 5 & $\begin{array}{l}\text { Pengembangan jalan disesuaikan dengan daya } \\
\text { dukung kawasan }\end{array}$ & & & & & & & \\
\hline 6 & $\begin{array}{l}\text { Pengembangan fasilitas pelayanan informasi dan } \\
\text { komunikasi }\end{array}$ & & & & & & & \\
\hline 7 & Pengembangan jaringan Air bersih & & & & & & & \\
\hline
\end{tabular}

Sumber: Data Primer 2017

Hasil penelitian berdasarkan indikator persepsi dalam pengembangan aksesibilitas, dari 7 kriteria penilaian adalah berada pada kategori sangat setuju (SS) dengan nilai sebesar $(3830,2)$. Data tersebut menjelaskan bahwa masyarakat memiliki pemahaman yang sangat baik bahwa pengembangan aksesibilitas juga sangat diperlukan, menurut salah satu responden mengemukakan bahwa ada beberapa pengunjung yang saat berkunjung ke objek Air Terjun sempat memberikan pendapatnya bahwa, sangat kerepotan ketika harus berjalan cukup jauh hingga ke lokasi Air Terjun dengan kondisi jalan yang belum tertata secara baik. Tentunya hal tersebut sangat berpengaruh juga terhadap kenyamanan dan kepuasan berwisata. Kondisi aksesibilitas juga mempengaruhi minat dan motivasi kunjungan wisatawan. Di samping itu kelengkapan objek mulai dari atraksi, amenitas dan aksesibilitas merupakan satu keterpaduan yang saling melengkapi ketika objek sudah mulai diminati untuk dikunjungi oleh wisatawan (Damanik dan Weber, 2006).

Pendapat lainnya dikemukakan dalam penellitian Widodo (2016) bahwa adanya penurun minat dan jumlah kunjungan ke objek wisata Pantai Tanjung Karang Kabupaten Donggala sangat dipengaruhi oleh kurangnya fasilitas dan aksesibilitas dalam mendukung aktifitas wisatawan.

\section{Partisipasi Masyarakat Desa Ureng}

\section{Partisipasi Masyarakat Dalam Perencanaan}

Partisipasi masyarakat dalam perencanaan merupakan suatu bentuk aksi nyata yang dilakukan oleh masyarakat dalam 
perencanaan, dalam bentuk terlibat dalam musyawarah, memberikan gagasan, ide, pendapat dan kritikan terkait dengan pengembangan objek wisata Air Terjun partisipasi masyarakat dalam perencanaan pengembangan dilakukan melalui 7 (tujuh) indikator pertanyaan yang tersaji pada Tabel.5:

Manusama. Dalam mengungkapkan

Tabel 5.Indikator Partisipasi Masyarakat Dalam Perencanaan Pengembangan.

\begin{tabular}{|c|c|c|c|c|c|c|c|c|}
\hline \multirow[t]{2}{*}{ No. } & \multirow{2}{*}{$\begin{array}{c}\text { Partisipasi Masyarakat Dalam Perencanaan } \\
\text { Pengembangan }\end{array}$} & \multicolumn{7}{|c|}{ Skor Penilaian } \\
\hline & & $\begin{array}{l}\text { SS } \\
\text { (7) }\end{array}$ & $\begin{array}{c}S \\
(6)\end{array}$ & $\begin{array}{l}\mathrm{AS} \\
(5)\end{array}$ & $\begin{array}{l}\text { BS } \\
\text { (4) }\end{array}$ & $\begin{array}{l}\text { KS } \\
\text { (3) }\end{array}$ & $\begin{array}{l}\text { TS } \\
\text { (2) }\end{array}$ & $\begin{array}{l}\text { STS } \\
\text { (1) }\end{array}$ \\
\hline 1 & $\begin{array}{l}\text { Bersedia terlibat dalam pertemuan bersama } \\
\text { seluruh masyarakat terkait rencana pengembangan } \\
\text { ekowisata Air Terjun Manusama. }\end{array}$ & & & & & & & \\
\hline 2 & $\begin{array}{l}\text { Bersedia terlibat dalam } \text { memberikan } \\
\text { ide/saran/kritikan, terkait proses } \text { perencanaan } \\
\text { pengembangan. }\end{array}$ & & & & & & & \\
\hline 3 & $\begin{array}{l}\text { Bersedia untuk menerima perubahan rencana yang } \\
\text { intinya menunjang pengembangan ekowisata }\end{array}$ & & & & & & & \\
\hline 4 & $\begin{array}{l}\text { Bersedia terlibat dalam perencanaan } \\
\text { Pengembangan objek dan atraksi }\end{array}$ & & & & & & & \\
\hline 5 & $\begin{array}{l}\text { Bersedia terlibat dalam perencanaan } \\
\text { pengembangan amenitas dan fasilitas }\end{array}$ & & & & & & & \\
\hline $\begin{array}{l}6 \\
7\end{array}$ & $\begin{array}{l}\text { Bersedia terlibat dalam perencanaan } \\
\text { pengembangan aksesibilitas }\end{array}$ & & & & & & & \\
\hline & $\begin{array}{l}\text { Bersedia terlibat dalam perencanaan } \\
\text { pengembangan sarana prasarana komunikasi dan } \\
\text { air bersih }\end{array}$ & & & & & & & \\
\hline
\end{tabular}

Sumber: Data Primer 2017

Hasil analisis partisipasi dalam nama objek, jalan setapak dan parkiran. perencanaan, menunjukkan skoring $(3002,4)$ dengan kriteria sesuai (S), data tersebut dapat menjelaskan bahwa partisipasi masyarakat Desa Ureng dalam perencanaan tergolong aktif. Hal ini didukung hasil wawancara dengan beberapa masyarakat yang mengemukakan bahwa pengembangan objek Air Terjun ini awalnya disponsori oleh pemuda mesjid, yang diatur dalam pengembangan papan Dalam proses perencanaan masyarakat selalu mengawali dengan musyawarah dalam menentukan rencana pengembangan, ide dan saran serta kritikan selalu mengawali keputusan yang akan dilakukan dalam pengembangan objek. Pengembangan objek Air Terjun Manusama ini mengalami proses dan berjalan secara bertahap.. 
Pengembangan objek lebih ddifokuskan pada kebutuhan yang dapat menunjang aktifitas dan kenyamanan pengunjung antaralain; kamar mandi, jembatan, tempat jualan kebutuhan makan/minum dan parkiran. Dengan semakin banyaknya pengunjung berkorelasi dengan adanya proses pengembangan yang lebih baik dan terarah, sehingga pengembangan menuju pada kondisi objek yang memiliki nilai jual tinggi semakin terwujud. Hal yang sama juga dikemukakan dalam hasil

\section{Partisipasi Masyarakat dalam Pengelolaan Objek}

Indikator pertanyaan terkait penilaian partisipasi masyarakat dalam pengelolaan

\begin{tabular}{|c|c|c|c|c|c|c|c|c|}
\hline \multirow[t]{2}{*}{ No. } & \multirow[t]{2}{*}{ Partisipasi Masyarakat Dalam Pengelolaan } & \multicolumn{7}{|c|}{ Skor Penilaian } \\
\hline & & $\begin{array}{l}\text { SS } \\
(7)\end{array}$ & $\begin{array}{c}S \\
\text { (6) }\end{array}$ & $\begin{array}{l}\text { AS } \\
(5)\end{array}$ & $\begin{array}{l}\text { BS } \\
(4)\end{array}$ & $\begin{array}{l}\text { KS } \\
\text { (3) }\end{array}$ & $\begin{array}{l}\text { TS } \\
(2)\end{array}$ & $\begin{array}{c}\text { STS } \\
(1)\end{array}$ \\
\hline 1 & $\begin{array}{l}\text { Bersedia terlibat dalam pengelolaan sebagai } \\
\text { penjaga kawasan. }\end{array}$ & & & & & & & \\
\hline 2 & $\begin{array}{l}\text { Bersedia terlibat dalam pengelolaan sebagai } \\
\text { petugas loket karcis, tukang parkir, guide lokal. }\end{array}$ & & & & & & & \\
\hline 3 & $\begin{array}{l}\text { Bersedia terlibat sebagai penjual makanan dan } \\
\text { minuman bagi pengunjung objek }\end{array}$ & & & & & & & \\
\hline 4 & Bersedia terlibat sebagai penyedia homestay & & & & & & & \\
\hline 5 & Bersedia terlibat dalam promosi objek Air Terjun & & & & & & & \\
\hline 6 & Bersedia terlibat dalam penyedia & & & & & & & \\
\hline 7 & transportasi roda dua. & & & & & & & \\
\hline
\end{tabular}

Sumber: Data Primer 2017

Berdasarkan pada hasil analisis dari indikator di atas, diperoleh nilai dengan kriteria sangat sesuai (SS), sebesar $(3864,4)$. Nilai tersebut memberikan indikasi bahwa partisipasi masyarakat penelitian Kanuna, (2014) bahwa pengembangan kawasan wisata harus terencana, bertahap menyeluruh untuk dapat memperoleh manfaat yang optimal bagi masyarakat. Sedangkan dalam Penelitian Rahlem et al., (2017) menjelaskan bahwa partisipasi masyarakat dalam merencanakan pengelolaan wisata berupa kontribusi yang dilakukan dalam mengurus objek wisata mulai dari musyawarah hingga pelaksanaannya.

Air Terjun Manusama disajikan pada Tabel.6. 
tetapi masyarakat menyadari bahwa adanya pengembangan dalam menunjang aktifitas dan daya tarik objek Air Terjun

Peran serta tersebut sudah mulai dilakukan oleh masyarakat, berdasarkan hasil wawancara dengan tokoh pemuda dijelaskan bahwa indikator pengelolaan masalah keamanan dan kenyamanan desa merupakan masalah prioritas yang harus tetap terjaga dengan baik, dan terhindar dari aksi-aksi yang menakutkan. Selain itu peran serta dalam menjaga ekosistem sekitar dari aksi penebang dan perusakan ekosistem juga sudah dilakukan oleh

\section{KESIMPULAN DAN SARAN KESIMPULAN}

Secara keseluruhan dapat disimpulkan bahwa persepsi masyarakat terhadap pengelolaan ekowisata Air Terjun Manusama di Desa Ureng Kabupaten Maluku Tengah tergolong baik.

\section{SARAN}

1. Perlu adanya sosialisasi terkait ekowiata dan konservasi lingkungan yang lebih intens kepada masyarakat Desa Ureng sehingga ada peningkatan pemahaman masyarakat dalam menunjang konservasi objek daya tarik kawasan.

2. Perlu melakukan promosi secara berkala dalam berbagai bentuk
Manusama dibutuhkan peran serta yang maksimal dari seluruh elemen masyarakat.

seluruh masyarakat. Masyarakat Desa Ureng juga menyadari bahwa daya tarik air terjun sangat ditentukan oleh kondisi debit air, sehingga perlu ditunjang dengan menjaga ekosistem daerah hulu hingga hilir dari penebangan liar atau perusakan. Pengelolaan yang baik dan optimal oleh seluruh komponen masyarakat akan tercipta kondisi objek yang memiliki nilai jual tinggi.

Berdasarkan hasil analisis penelitian dan pembahasan yang telah dilakukan menunjukkan, bahwa persepsi masyarakat terhadap perencanaan pengembangan dan pengelolaan ekowisata memiliki indikator penilaian sesuai (S) dan mendukung.

misalnya melalui web site; leaflet, spanduk/brosur (yang diletakan pada Banda atau Pelabuhan). Sehingga mempengaruhi tingkat kunjungan ke objek.

3. Perlu melakukan koordinsai dengan dinas-dinas terkait dalam upaya pengembangan. 


\section{DAFTAR PUSTAKA}

Avenzora R. 2008. Penilaian potensi objek wisata : aspek dan indikator penilaian. $\mathrm{Di}$ dalam:

Brahmantyo H, Baiquni M, Fandeli C, Widodo T. 2017. Persepsi masyarakat setempat dan pegawai pemerintah daerah

Hijriati E, Mardiana R. 2014. Pengaruh ekowisata berbasis masyarakat terhadap perubahan kondisi

Kanuna, R. S. 2014. Peranan Pemerintah Daerah Dalam Pengelolaan Potensi Pariwisata Di Kabupaten Toraja Utara. Skripsi Fakultas Ilmu Sosial

Marpaung, H. 2017. Pengaruh Daya Tarik dan Aksesibililtas Terhadap Minat Berkunjung Wisatawan Ke Air

Rahlem, D.Yozadan, D. Arlita, T. 2017. Persepsi Pengunjung dan Partisipasi Masyarakat

Sugiyono. 2010. Metode Penelitian Bisnis (Pendekatan Kualitatif, Kuantitatif

Widodo, E. 2017.Pengembangan Atraksi Wisata Pantai Tanjung Karang Sebagai Kawasan Wisata
Avenzora R,editor. Ekoturisme Teori dan Praktek. Aceh (ID): BRR NADNias. hlm 249-252.

terhadap dampak pembangunan pariwisata: studi kasus di kawasan

Kota Tual.Jurnal Khasanah Ilmu. 8(1):1019.

ekologi, sosial dan ekonomi di Kampung Batusuhanan, Sukabumi. Sosiologi Pedesaan. 2(3):146-199.

dan Ilmu Politik Universitas Hasanuddin. Makasar.

Terjun Ponot Di Desa Tangga Kecamatan Aek Songsongan. Kabupaten Asahan. Prosiding Seminar Nasional Multidisiplin Ilmu UNA 2017.

Dalam Pengelolaan Ekowisata Air Terjun Aek Martua Di Kabupaten Rokan Hulu Jurnal JOM Faperta. Vol.4 No.1 Februari 2017.

dan R\&D). Bandung (ID): Alfabeta.

Bahari Di Kabupaten Donggala. Jurnal Katalogis, Volume 5 No. 4, April 2017. 206-215. 